\title{
EESTI LOODUSLIKUD PÜHAPAIGAD SUULISES JA KIRJALIKUS KULTUURIS „KALEVIPOJA” NÄITEL
}

\author{
OTT HEINAPUU
}

$\mathrm{L}$ ooduslikke pühapaiku mõtestatakse, kirjeldatakse ja kujutatakse suuliselt levinud folkloorsetes tekstides teisiti kui eesti kirjakultuuri tekstides. Eesti kirjakultuuri on ühe tüvitekstina oluliselt mõjutanud Friedrich Reinhold Kreutzwaldi eepos „Kalevipoeg”, mis oma allikate poolest asub suulise ja kirjakultuuri piiri lähedal, kuid jääb siiski kirjakultuuri valda. Järgnevalt võtan vaatluse alla „Kalevipojas” esinevad viited looduslikele pühapaikadele, soovides heita valgust sellele, millist mõju on eepos ja selle metatekstid avaldanud looduslike pühapaikade ja vast ka laiemalt sümboolsete maastike representatsioonile tänapäeva eesti kultuuris. Siinne artikkel jätkab minu varasemaid ja üldisemaid käsitlusi (Heinapuu 2010, 2018) kultuuriliste murrangute ajel Eestis XIX sajandist alates toimunud looduslike pühapaikade ümbermõtestamisest, kuid võtab kitsamalt ja ehk täpsemalt fookusesse ühe teksti: vaatlen, kuidas ja millistes kontekstides esineb püha tammiku sümbol rahvuseeposes võrrelduna teistlaadi pühapaikadega. Et asetada käsitletud motiivid laiemale taustale, visandan esmalt üldisemalt looduslike pühapaikade kujutamise erinevused suulises ja kirjalikus kultuuris, tuginedes põhiliselt Walter J. Ongi ja Juri Lotmani kultuuritüpoloogia kontseptuaalsele raamistikule. Lõpetuseks puudutan kultuuritekstidest mõjutatud uute rahvuslike pühapaikade rajamise maastikupraktikaid ${ }^{1}$, et näitlikustada kirjutatud sõna maastikuks saamist.

Loodusliku pühapaigana mõistab rahvusvahelise looduskaitseliidu (IUCN) kaitsejuhend „maa- või veeala, millel on rahvastele ja kogukondadele eriline vaimne tähendus" (Looduslikud pühapaigad 2011: xxiv). Kohalikus vaates on muinsuskaitseseaduse järgi ajalooline looduslik pühapaik „olulise inimmõjuta rahvapärimuslik ohverdamise, pühakspidamise, ravimise, usulise või rituaalse tegevusega seotud asi või maa-ala. Ajaloolised looduslikud pühapaigad on olulised rahvapärimuskultuuri ning kohaliku identiteedi kandjad." (MuKS § 11 $\lg 6$ ) Eesti looduslike pühapaikade hoidmise ja uurimise arengukava võtab nende vormilise mitmekesisuse kokku nii: „Need võivad olla üksikud puud, puuderühmad ja metsad, allikad, jõed, ojad vm veekogud, erinevad maastikuvormid nagu künkad, orud, pangad, kivid, mitmesugused ohvripaigad jm. Looduslike pühapaikade hulka on arvatud ka ristipuud, millega seostub ajalooline matusekombestik." (Eesti looduslikud pühapaigad 2015: 3)

${ }^{1}$ Pean silmas, et kõik maastikud on protsessuaalsed ja kujunevad inimeste tegevuse mõjul. Maastikupraktikate kohta vt Ingold 2000: 189-208. 
Eesti looduslikud pühapaigad on kujunenud kohaliku maakasutuse mustri ning inimese ja looduse omavaheliste muutuvate (ka religioossete) suhete osana. Valdavalt XIX-XXI sajandil talletatud pärimusest tuntud pühapaiku on kujundanud praktikad, milles väljendub kohalik arusaamine loodusest ja üleloomulike vägede ning olendite tegevusest, elukohtadest ja harjumustest. Keeldudega on osaliselt piiratud maa ja loodusvarade kasutamine (nt kündmis- ja raiumiskeelud), tavad määravad kohti, kus pöörduda üleloomulike olendite poole ja anda neile ande või tähistada aastaringi pühi. Säärase nii negatiivse kui ka positiivse inimmõju tõttu võiks vähemalt osa looduslikke pühapaiku pidada ka poollooduslikeks (vt Heinapuu 2016: 164-169). Selline looduslike pühapaikade roll kultuuris on ilmselt kultuuritüpoloogiliselt omane agraarühiskondadele pärast neoliitilist revolutsiooni ja enne tööstusrevolutsiooni.

\section{Suuline ja kirjalik kultuur}

Lähtudes suulise ja kirjaliku mõtlemise põhimõttelisest erinevusest (Ong 2002), saab käsitada suulist ja kirjakultuuri Juri Lotmani kultuuritüpoloogia mõttes kultuuri erisuguste allsüsteemidena (Lotman 2010: 72). Traditsioonilise kogukondliku suulise kultuuri kõrval arenes eestikeelne autonoomne kirjakultuur XIX aastasajal ühes koolihariduse, kirjaoskuse ja ajakirjanduse levikuga. Ühiskeelse kirjakultuuriga sai võimalikuks eesti kultuur ja rahvuslus. Seda võib käsitada kultuuri uue allsüsteemina, mis võimaldas suhtlust ja tõlget seni eraldi eksisteerinud kogukondlike kultuurisüsteemide vahel ja seega ka uue eesti ühiskonna teket laiemal pinnal kujutletud kogukonnana Benedict Andersoni (2006) mõttes. Kirjakultuur muutus kultuurisüsteemis suulise kultuuri asemel selgelt domineerivaks allsüsteemiks XX sajandil.

Kultuurikood, milles toimisid looduslikud pühapaigad, oli suuline ja selles andsid tooni folkloorsed tekstid. Lotmani neljast kultuuritüübist (semantiline, süntaktiline, asemantiline-asüntaktiline, semantiline-süntaktiline, vt Lotman 2010: 36-60) võiks see kuuluda semantilisse ehk sümbolilisse kultuuritüüpi, mis on orienteeritud kogu inimest ümbritseva reaalsuse ja ka selle osade semantiseerimisele ehk keskkonnas tähenduste omistamisele ja sarnaneb keskaegse kultuuritüübiga (Lotman 2010: 40). Arusaamine maailmakorrast on seotud kohalugudega: konkreetsete paikadega seotakse kosmoloogilise sisuga lood, sh rahvusvahelise levikuga motiivid ja süžeed. Sel kombel maailma sidusust hoidev kohapärimus on „kultuurmaastiku objektide teket, nimesaamist jm seletav rahvatraditsioon, mis toimib eeskätt mingi kohaliku kogukonna kollektiivse eneseteadvuse toetajana" (Remmel 2014: 13). Suur osa mütoloogilistest teadmistest võibki edasi kanduda lühikestes kohapärimuslikes lugudes, mis on kinnistatud konkreetse maastiku külge ja isiklikku kogemusse. Võtame näiteks loo ühest Rapla-lähedasest teeäärsest kivist:

Kalevipoeg visand sinna selle kivi. Jaanilaupäeva öösel näinud Kalevipoeg Hiiemäelt, Palukülast, et hunt seal varssa murdnud. Ta tahtnud hunti kiviga surmata, kuid kivi matnud ka varsa oma alla. Nüüd kuuldakse selle kivi alt iga jaanilaupäeva öösel kell 12 hundi ulumist ja varsakella kõlksumist. Kivil 
on Kalevipoja sõrmejäljed praegugi näha. (Pühad kivid Eestimaal 2011: 142

(E StK 11, 39/40 (12) < Rapla khk - L. Pärt (1921))

Lugu ühendab maastikuobjekti ja selle läheduses kogetud üleloomulikud seigad muude oluliste nähetega. Kivi on seotud piirkonna keskse pühapaiga, Paluküla hiiemäega (mäge puudutavat hiiupärimust vt Laugaste, Normann 1959: 138-139; vt ka Koski 1967: 61, nr 448). Loo vähem kui viies tosinas sõnas sisaldub viide pühale ja ohtlikule ajale jaanilaupäeva öösel (mis on üleloomulike nähete poolest tüüpiliselt rikas), samuti hiid Kalevipojale (kelle tegemised seostuvad tihtipeale pühapaikadega; sageli on hiidude heidetud kive peetud pühaks ja vahel nimetatud hiiekivideks, vt Remmel 1998: 18). Loos aktualiseeruvad karjakasvataja igapäevased kiskjatega seotud riskid, mis on rahvausu kujunemist mõjutanud, põimudes mütoloogiliselt olulise hiidude ja huntide vastasseisuga.

Säärased pärimuskillud koondavad rahvaliku teadmise eri külgi ja toimivad tihendatud mnemooniliste abivahenditena, mis aitavad maailma paremini mõista. Kirjapanduna ja kirjakultuuri kaudu tõlgendatuna võivad säärased muistendid tunduda arusaamatutena, kui kosmoloogia seletamise põhiline mudel on hierarhiliselt struktureeritud ja kirjalikult jäädvustatud mahukas tekst. Nii on mõistetav kosmoloogilist süsteemi pigem pika tekstina mõtestava kirjakultuuri igatsus fikseeritud ja struktureeritud pühakirjade ja eeposte järele ning nõutus üksikute mütoloogiliste pudemetega kokku puutudes.

Vene keskaegsel kultuuril põhinev semantilise kultuuritüübi kirjeldus märgib, et see „maailmapilt oli põhimõtteliselt akrooniline” (Lotman 2010: 46). Toodud lugu seob ühe rändrahnuga mitu ajahetke: selle saabumine üleloomuliku viskega kunagi muiste; igal aastal korduv jaaniöö, kui kivi juures võib hääli kuulda; praegune aeg, kui igaüks võib näha Kalevipoja sõrmejälgi. Selline lugu aktualiseerub kõige elavamalt, kui kivi näha, kuid samuti kivist mööduva teekonna kirjeldamisel või jaaniööga seoses. Muistend ei organiseeri sündmusi mitte kronoloogiliselt, vaid mütoloogiliselt, meenutades maastikuobjekti sünni aega ja tõstes esile korduvaid erilisi pühi aegu.

Folkloorses kultuurikoodis edastatavate sõnumite ajalooline sügavus sõltub suulisest mälust ja seetõttu ei ulatu ajas nii kaugele kui klassikalise kirjakultuuri võimalik ajalooline sügavus. Mälestused, mis ei seostu enam olevikuga, ununevad. Seega on suulise kultuuri ajalootaju teistsugune: minevikust ei hoita alles fakte, mis pole enam kultuuriliselt olulised (Ong 2002: 46-48). Suuline ajalooline mälu on paratamatult ebatäpne: üksikisiku kogemusest kaugemale jäävate minevikusündmuste ajas paika panemisel tekib pärimuses vigu ja ebamäärasusi, kaugem minevik sulab kokku muistseks ajaks.

Möödunud aega hakati tajuma ühe kõiki sündmusi ajalisse järgnevusse seadva loona pärast nende kirjalikku dokumenteerimist, aastast aastasse tähtsündmusi loendavate kroonikate kirjutamist. Lõplikult kinnistus selline aja tajumisviis alles pärast trükiste laiemat levikut (Lowenthal 1985: 220 222). Sel taustal on mõistetav, kuidas püha puu võib olla pärimuse järgi kasvama läinud nii muistse hiiu kui ka Põhjasõja-aegse valitseja maasse torgatud kepist. Kalevipoeg esineb tammede istutaja rollis Kuremäel, kus asub kuulus püha tamm (Eisen 1920: 95-96), Rootsi kuningas või Karl XII vähemalt 115 puu juures, Vene keiser, Peeter I või keisrinna Katariina kümne puu juures, 
samuti olla puid istutanud neitsi Maarja ja vanapagan (Puss 1995: 9-12). Põhjasõja sündmuste kajastused ei seisa pärimuses kaugel mütoloogiast ega maastiku kujunemise algaegade lugudest.

Suulised kultuurid on alalhoidlikud, innovatsioon ja originaalsus avalduvad neis teisiti kui kirjaliku dominandiga kultuurides. Lotmani järgi pole neis „põhimõtteliselt võimalik uute ja samas tõeste tekstide loomine. Uus tekst on alati avastatud vana”. Kunstniku roll on avastada „eelnenu ja igavene”, tal on õigus „astuda vahendaja, „ilmutaja” rolli, mille kaudu igavesed ja ettemääratud tähendused peavad maailmale ilmnema". (Lotman 2010: 46) Olemasolevaid teadmisi tuleb korrata, et teadmised ei kaoks ega ununeks; teadmine, mida suhtluses ei korrata, on kiire kaduma. Kirjaoskus ja veel rohkem trükikunsti levik vähendab suulise mälu kandjate ja vanade teadmiste kordajate prestiiži nende arvel, kes midagi uut avastavad (Ong 2002: 40-41). Uued tähendused ja muud suulise kultuuri sisemised muutused näitavad Ongi sõnul, et originaalsus on siiski võimalik ka korduvatele vormelitele ja standardsetele teemadele toetuvas mõtteilmas. Neid uuendusi ei esitleta uuendustena, vaid traditsioonidele vastavatena: innovatsioonile leitakse õigustused traditsiooni kaudu (Ong 2002: 41-42).

Vanad pühapaigad võivad ununeda mõne põlvkonna jooksul pärast aktiivse kasutuse lõppemist, kuid samuti võidakse käibele võtta uusi, mis ajalooteaduse seisukohalt lühikese aja jooksul võivad muutuda mäletamata aegadest pärinevateks traditsioonilisteks pühapaikadeks. Ilmselt seotakse uute pühapaikadega vanu ja rahvusvaheliselt levinud rahvajutumotiive (nt peidetud varandus, kiviks või puuks muutunud inimene, härgade veetud või kohale lennanud mägi, vt Eisen 1996 [1918]: 49-54), mis toimivad paiga pühaduse staatuse märkidena.

\section{Kirjalik kultuurikood ja looduslikud pühapaigad}

Kirjakultuuri levikuga kahaneb muististe olulisus kultuuris, märgib David Lowenthal. Mälu kandjatena jäävad muististega seotud lood alla kirjutatud ajaloole. XX sajandi Eestis pole mineviku seletamisel maastikumärgid, nagu hiiu heidetud kivid, enam nii olulised - minevik seotakse lahti nähtavast maastikust. Olulisemaks muutub rahvuskeskselt kirjutatav ajalugu. Pärimuslikest maatundmise viisidest täpsemate ning erinevalt pärimusest füüsiliste artefaktidena fikseeritud kaartide levides väheneb teisalt vajadus kasutada muistiseid maamärkide ja piiritähistena, mille järgi orienteeruda või valduste ja kinnisasjadega seotud õiguste ulatust määrata (Lowenthal 1985: 255-257).

Kirjalik kultuurikood on tsentraliseeriv. Eesti rahvuse ülesehitamine tänapäevases mõttes sai võimalikuks pärast selle koodi juurutamist. Lotmani klassifikatsioonis kuulub see süntaktilisse kultuuritüüpi: „Kultuurilise tähtsuse tunnuseks kujuneb kuulumine mingi terviku juurde: eksisteerida tähendab olla osa. Tervik pole väärtuslik seetõttu, et sümboliseerib midagi sügavamat, vaid iseeneses - seetõttu, et ta on kirik, riik, isamaa, seisus." (Lotman 2010: 48) Eesti rahvust ehk tervikut, millesse inimesed ja kultuurinähtused osana kuuluvad, hakkasid haritlased teadlikult looma XIX sajandil. Rahvuse hierarhilises süsteemis vajalikeks komponentideks saavad selle loojate mee- 
lest lisaks kirjakeelele veel ajalugu ja eepos. Õpetatud Eesti Seltsi estofiilist liige Georg Julius Schultz-Bertram küsis 1839. aastal peetud kõnes: ",Kuidas peab nüüd meie Selts ühe täisealiseks kuulutatud, pärisorjusest vabastatud ja ometi oma mittetäisealisuse ja julgusetuse koorma all edasi ägava rahva valgustamist ja vaimset taassündi kõige jõudsamini edendama?" Ja ta oli ise vastanud: „Ma arvan, kahe asja läbi. Anname rahvale eepose ja ajaloo, ja kõik on võidetud!"' (Oinas 1994: 33) Rahvuste kujunedes (Ladina-Ameerikas ja Euroopas valdavalt XIX sajandil, Euroopa kolooniates XX sajandil, vt Anderson 2006) süsteem aegapidi kasvab, selle komponentideks saavad Eestis omakeelne haridus (sh ülikool), oma riik jm institutsioonid rahvusooperi, -balleti, -raamatukogu ning rahvusteaduste õppetoolideni. Rahvuse kui süntaktilisse kultuuritüüpi kuuluva süsteemi iga üksiku elemendi omadused pole nii olulised kui süsteemi elemendi olemasolu ise (eepos või ballett on igapäevakommunikatsioonis perifeersed). Kohustuslike osade nimekiri on kokkuleppeline, ajas muutuv ja rahvuseti erinev.

Rahvuse ehituskividena on kasutatud erisuguseid kultuuritekste. Olulist osa on mänginud laia leviga ajalehed, nagu Postimees ja Sakala, ja nende kaudu levinud poliitilised tekstid, kuid ka rahvusromantilised kunstilised tekstid, nagu Kreutzwaldi „Kalevipoeg” (Kreutzwald 2003 [1862]) ja teiste poeetide lüürilisem isamaaluule. Kirjakultuuril põhinev kultuurikood on väga ajalooteadlik. C. R. Jakobsoni 1868. aastal peetud aastaarvudega pikitud isamaakõnest on läinud käibele 700-aastase orjaöö motiiv, mis on ajavahemikuna üsna täpselt määratletud ja on eesti rahvusliku ajaarvamise üks tihedamini kasutatavaid mõõte. Eesti rahvusliku identiteedi ja ideoloogia kujundamisel on olnud otsustav roll ka ilukirjandusse kuuluvatel ajaloolistel jutustustel ja romaanidel, mis kujutavad rahvuse ajaloo pöördelisi sündmusi (Laanes, Kaljundi 2013; Tamm 2012: 60-61, 65-81).

\section{Kirjakultuur põimub kohaliku suulise pärimusega}

Hiiekohad, mida tuntakse valdavalt XIX-XXI aastasajal kogutud ja fikseeritud suulise pärimuse varal, on rahvusliku ajaloo ja ideoloogia uues süsteemis leidnud oma koha muinasaegse, ristiusueelse ajaloo lahtris. Neis nähakse ristisõjale eelnenud ajaloo ühte kehastust, kuigi napib usaldusväärseid allikaid, mille toel suulises pärimuses tuntud paiku nii kauge minevikuga tõsikindlalt või isegi usutavalt siduda. Kuna looduslikest pühapaikadest on keskaegsetes ajalooallikates juttu põgusalt ja ebamääraselt, on see tinginud vajaduse täita lünki oletustega muistsete pühapaikade kohta. Osa oletusi omakorda on läinud liikvele kindlate faktide pähe.

Üks selline näide on Ebavere mäe seostamine Henriku Liivimaa kroonikas esitatud looga, kuidas Tharapita lendas Saaremaale ühelt kauni metsaga Virumaa mäelt, kus ta kohalike jutu järgi sündinud oli. Kroonika andmeil raiusid misjonärid mäel maha jumalate pildid ja kujud, mille peale kohalikud imestanud, et need ei veritse (HCL XXIV 5: 216). Pastor Georg Magnus Knüpffer identifitseeris Henriku viidatud paiga Ebavere mäena pärast VäikeMaarja kihelkonna elanikelt kohalugude kogumist (Jonuks 2007). On ka arvatud, et Henrik võis viidata Sinimägedele (Sutrop 2002: 7); õigupoolest võinuks 
olla tegu ka mõne muu Virumaa rajamaade hiiemäega (vt võimalikke paiku Koski 1967: 62-65, nr 501-555).

Knüpfferi hüpotees on käibel eestikeelses kirjanduses ja sealtkaudu on see jõudnud kohapärimuse vastu huvi tundvate haritud inimeste teadvusse. Seetõttu on see hakanud tulema teise ringi pärimusena rahvaluulekogudesse rahvajuttude üleskirjutuste kaudu, kus sellele viidatakse kui pärimust legitimeerivale motiivile. M. J. Eiseni korrespondent J. Karelson Ambla kihelkonnast kirjutab: „Virumaal, kolm versta Väike-Maarja kiriku juurest, Vao mõisa maa peal on Ebavere mägi. See mägi, mille harjal vanal ajal kuulus hiiemets kasvanud ja mille all vanad eestlased oma avitaja Taara ees käinud palvetamas." Seejärel esitab ta rahvaehtsa ilmega loo Ebavere mäe jalamile eksinud õitsilisest, kes nägi seal uhket linna, kust ta ostis pastlad, nahkkindad ja vöö ning jõi kõrtsis õlut. Ärkamise järel oli linn kadunud, kuid pastlad-kindadvöö alles (Eisen 2000 [1958]: 81-82). Siin kohtub muinasteaduse hüpoteesiga rahvusvaheline jutusüžee, kus inimene satub üleloomulike olendite (nt haldjate, kuradite, maa-aluste) peole, ent pärast ärkamist näeb, et uhke peopaik on kadunud. Sama rahvusvaheline süžee on seotud hulga teiste paikadega; näiteks on peategelane hommikul avastanud ennast kivil keset Ülemiste järve või järve kõrval. ${ }^{2}$

Nii on Henriku kroonika teade saanud kirjalike allikate vahendusel osaks kohalikust pärimusest, mis ei toimi enam puhtalt suulise süsteemina, vaid vastastikmõjus kirjakultuuriga. Umbes samasuguse mehhanismi kaudu, nagu Ebavere mäe identifitseerimine kroonikas mainitud paigana, pannakse sobivad XIX-XX sajandi suulise maastikupärimuse elemendid tähistama kaugemat rahvuslikku minevikku, mille ajalugu kirjutatakse suures osas kroonikate ja muude baltisaksa tekstide põhjal (seda nii „Kalevipojas” kui ka näiteks Eesti „muinasparlamendi” paigutamisel Raikkülla, vt Metssalu 2008). Sealjuures võib paikadega suulises kultuuris seotud pärimusvara jääda kirjakultuuri motiivide varju (Ebavere mäge mainitakse praegu rohkem Henrikule viidates muistsete eestlaste palvepaiga kui üleloomuliku linna asupaigana), nii et pärimus allutatakse rahvusliku ajaloo kaanonile. Pärimuspaiku on hakatud tõlgendama ja tutvustama rahvusliku ajaloo kaudu, samal ajal kui suuline pärimus lähtub pigem kohalikust vaatest.

\section{Kättesaamatute tammikute istutamine eesti kultuuri}

Kultuuri kalduvus mitmekeelsusele ilmneb ka „Kalevipojas” (Kreutzwald 2003 [1862], edaspidi viited lugudele ja värssidele), mille kokkupanemisel on kasutatud kultuuri eri allkeeltes käibinud tekste. Seetõttu on tekst kasutatavate kultuurikoodide poolest eripalgeline. August Annist eristab Kreutzwaldi loodusekujutuses kolme kõnelemise viisi: „naiivürgset” ehk rahvalikku, mis sarnaneb folkloori konkreetse ja napisõnalise loodusekujutusega ning pigem viitab ja loendab, kui kirjeldab, ja seejärel kaht Kreutzwaldi kui poeedi isikupärasemat loodusekujutuse viisi, mida Annist seostab vastavalt vararomanti-

${ }^{2}$ Vt nt EKM ERA, E 28357 (20) < Tõstamaa khk, Pootsi v - Otto Schantz < Madis Schantz (1896). 
lise ja klassitsistliku traditsiooniga (Annist 2005: 829-831). See kolmikjaotus peegeldab ka looduslike pühapaikade kujutamist eeposes. Annist märgib rahvalik-naiivse ja Kreutzwaldi isikupärasema ratsionalistlik-sentimentaalse loodusekujutuse vahelist ebakõla, mis tähistabki veelahet suulist ja kirjalikku tüüpi tekstide vahel. „Kalevipoja” rahvalikumas loodusekujutuses on palju ühist kohapärimuslike muistendite loodusepildiga, kuna suure osa eepose tekstist moodustavadki kreutzwaldlikku regivärssi ümber pandud kohamuistendid. Siia kuuluvad näiteks Ülemiste järve ja selle keskel oleva kivi tekkelugu, mida ka vanem pärimus seostab üleloomulike nähetega (II: 443-479), ja Linda muutumine ohvrikiviks, mis on tuntud Iru ämmana (III: 374-383, Iru ämmaga seotud pärimust vt Remmel 2005; Laugaste, Normann 1959, nr 179), samuti lugu sellest, kuidas Raudoja saab alguse surnud nõianeitsist (XV: 260-419). Konkreetse paigaga sidumata ja kunstipärasem - kuid siiski muistendivõtmes - on lugu, kuidas Kalevipoeg künnab ja väsib, heidab mäekaldale puhkama ning tema higist sünnivad allikad, kust saab väsimuse ja valu vastu kosutust, parema silmanägemise ja jume (VIII: 737-778).

Annisti hinnangul võib eepose looduskujutust iseloomustada „kui võrdlemisi klišeelist ja üldsõnalist ning peajoontes mitte just eesti- või rahvalaulupärast”. Ta lisab, et Kreutzwaldi „isiklik, meeleolutaotlev looduskujutus seevastu on paiguti õige tunderikas, eriti öö ja kaugusvaadete luulenduses, ja etendab võrdlemisi suurt osa eepose kui terviku meeleolulisel ilmestamisel”. Siin esineb paksudes värvides edasi antud tundelisi õhkamisi ning Taara tammik kui hingemaastik, samuti muud kaduvikku rõhutavad hingematvad maastikud. Säärased lüürilised värsid esinevad eepose lugusid raamivates sissejuhatustes monoloogidena „vana lauliku” ehk eepose fiktiivse esitaja suus. (Annist 2005: 829-830)

Monoloogides tulevad jutuks ka Taara tammikud ja märgilised tammed: „Kuulge juttusid jumekaid, [---] Mis mulle puistand pihlakasta, / Tulnud teised toomingasta, / Taara tamme tüvikusta" (Sissejuhatuseks: 302, 307-309); „Veeretelen vanu viise, / Mis ma Harjusta arvasin, [---] Taara hiiesta tabasin” (VIII: 68-69, 72); „Taeva küünal, ehatähti, [---] Vaikselt vaatas sinu silma / Muistepõlve muudendusi, / Vaatas Taara tammikuida, / Hiiepuida ilusaida / Haljendavas leheehtes" (VIII: 1, 7-11). Laulik kinnitab, et Kalevipoja-lugusid tuntakse üle maa, loeb üles kõik maakonnad ja nimetab ka Taara tammikuid: „Mine, poega, Pärnumaale, [---] Taara tammiku tahaje, [---] Igas paigas idanevad / Kalevipoja sõnumid” (II: 92, 98, 101-102). Nagu Annist on näidanud, oli vana lauliku kuju eelromantilises Euroopa eepikas laialt levinud ja Kreutzwaldi lauliku üks eeskuju näib olevat James Macphersoni „Ossiani laulude" nimikangelane (Annist 2005: 611-614).

Kolmas loodusekujutamise viis esineb eepose muinasjutulikes-seikluslikes osades ja ligineb stiililt klassitsismile, Annist seostab seda koidu ja keskpäeva meeleoluga (Annist 2005: 829). Kalevipoeg on siin muinaseesti kuningas, kes elab Taara hiie lähedale ehitatud linnuses, laseb laevasõidu kordaminekuks ohverdada Uku kivile ja kogub sõjaretke eel oma sõjaväe Taara tammikusse. Siin kujundavad looduslike pühapaikadena antiikset-heroilist meeleolu Taara hiied või tammikud ja Uku kivid. Pühad tammesalud meenutavad antiikse Kreeka või Rooma piksejumala pühamuid. Eepose kirjeldused Uku kivile 
ohverdamisest sarnanevad „Iliases” kujutatud kreeklaste ohvritalitustega (nt Homeros 1960: 31-32, teise laulu värsid 394-431).

Sellist antiikeepose väärilist pühapaigakujutust võib näha pärast Kalevipoja võitu oma vendade üle jõukatsumisel Saadjärve-äärses hiies („Paistis päevaveeru vastu / Taara ilus hiiekene, / Mäeharjalt haljendelles / Läikivailla lehtedella. / Õnnerikkas orus voolas / Emajõgi väsimata" (VIII: 236-241)). Võidu järel kraabib Kalevipoeg ohvrianniks hõbevalget Vetevaimule. Episood märgib kangelase saamist maastikku kujundavast hiiust kuningaks, kuid põhineb kohapärimusel: Kalevipoja visatud ohvrikivi ja Saadjärve-lähedane hiis, mille kohalik mõisahärra hävitada lasknud, on pärimusest tuntud (Meriste 1976). Teine ruumis konkreetsemalt juhatatud Taara pühamu on eepose tekstis Taaramägi Emajõe ääres, millele Kalevipoeg ehitas oma linna („Teise linna Taaramäele, / Emajõe kalda äärde, / Varjuks Taara varvikulle” (X: 787-789); „Kutsus rahvast kauge'elta / Taaramäele mängimaie” (XII: 484485); „Tulin hilja Taara mäelta” (XV: 510)). Siin on ilmselt silmas peetud Tartu Toomemäge ja küllap sama kohta on eeposes kutsutud „Taara paigaks” („Laevad tulid Ema laineil / Lustil veteveeretusel / Peipsi rannast Taara paika” (XII: 487-489)) ja „Taara aiaks” („Jumalaga, Taara aeda, / Emajõekene ilusa!” (VIII: 582-583)).

Ülejäänud tammesalud, mis meenutavad antiikseid piksejumala pühakohti (vrd ka Philostratose kirjeldust Zeusile pühendatud Dodone tammikust teoses „Eikones” II: 33, Philostratorum 1825: 103), jäävad eeposes asukohalt ebamäärasemaks. Eestist välja, vast Norrasse, saaks paigutada Taara tammemetsa Kalevi kodumaal: „Põhja piiril seisis pere, / Tugev talu kaljudella / Taara tammemetsa ääres” (I: 80-83). Ühtlasi öeldakse samas: „Kange Kalevite seltsi, / Mehed kui tammed tugevad” (I: 78-79). Sama võrdlust kasutab autor palju kordi vormelina Kalevipojale viidates.

Ülejäänud kolme mainitud Taara tammikut võib ruumilise ebamäärasuse tõttu pidada üheks ja samaks paigaks või sama hästi kaheks või kolmeks eri paigaks. Kõik kolm esinevad Kagu-Eesti, Vene-Läti piirimaade ning Pihkvaja Peipsi-lähedaste paikade kontekstis. 19. loos tuuakse valitseja Kalevipojale sõjasõnumeid: „Pihkva piirilt tõttas poissi, / Teine Läti lagedalta, / Teiselt poolt Taara tammikut / Kurvastusta kuulutama, / Sõjalugu sõnaldama” (XIX: 755-759). Vastuseks Kalevipoeg „Sõitis sõjaratsu seljas / Tulist Taara hiie poole, / Kuhu väge kogutie” (XX: 233-235). Kalevipoeg toob ka ehituspuud Taara tammikust: „Kalev kandis koormakaupa / Linna tarbeks laudasida / Pikal teel Peipsi tagant, / Kandis kokku tarbepuida, / Tüvikuida tuhandeida / Vana Taara tammikusta" (XV: 595-600). Viimane värss on omapärane seetõttu, et püha ehk puutumatu metsasalu puude kasutamine ehituspuuks on eesti ja rahvusvahelises traditsioonis keelatud ning toob levinud uskumuse järgi kaasa pühade puude raiuja või siis tema pere kariloomade surma või haigestumise.

Eeposes mainitakse neljal korral Uku kivile ohverdamist. Enne linnaehituse alustamist ohverdab Olevipoeg Uku kivile (XV: 549-553). Kalevipoeg toob laevasõidu eel teadjad reisiõnne nimel ohverdama („Tarkasid veel tahetie, / Sõnamehi sunnitie, / Tuuletarku tarvitati, / Manatarku meelitati / Uku kivil ohverdama, / Teele õnne toimetama" (XVI: 281-286)), samuti soovitatakse Uku kivile ande anda enne laevaga teeleminekut (XVI: 1050-1056). 
Õndsa priiuseaja kirjelduses „Värsket leenta viidanekse / Uku kivile kingiksi” (XIX: 480-481). Siiski jäävad kõik viited Uku kividele ebamääraseks, nii et pole võimalik viidata ühegi konkreetse kivi asukohale.

Samasse muinasjutulisse-klassitsistlikku liiki võib eeposes lugeda pühade hiite ja tammede mainimised, mis ilmuvad lüüriliste motiividena lauludes, mis on ühe või teise eeposetegelase suhu pandud. Peale Kalevipoja enda kuuluvad lauljate hulka pseudomütoloogilised Murueide tütred. Sääraseid Taara tammikuid võib käsitada muinasjutuliste-fiktsionaalsete paikadena, millele tuntud geograafias ei peagi midagi vastama.

Seega esineb Taara tammik „Kalevipojas” pigem kättesaamatu idealiseeritud mineviku, muistse vabadusaja või meelerahu tähistajana, mitte konkreetselt määratletud paigana. Säärased motiivid ei viita üldiselt paikadele, kuhu oleks võimalik lugejal minna või mida kaardil näidata, vaid pigem kadunud minevikule, mida vana laulik taga igatseb, või mõnele muule abstraktsemale kujutlusele. See on iseloomulik ka teistele uuematele kultuuritekstidele, kus „Taara tammikut” kasutatakse samal kombel, kui Kreutzwaldi „vana laulik” seda teeb. Tihtipeale lisandub aimdus, et Taara tammikud on kunagi ammu maha raiutud, mispuhul võib lisaks viitele puuslike raiumisele Henriku kroonikas kahtlustada kaudset püha Bonifatiuse legendi mõju: seal raius hessenlaste juurde lähetatud misjonär maha püha tamme.

Kreutzwaldi ja tema kaasaegsete kirjutiste diskursusse kuulub C. R. Jakobsoni luuletus „Veel pole kadund kõik” (Linnutaja 1870: 11), mis ühendab muistse vabadusaja, rahva orjastamise ja vabadusaate kaasaegse jalge alla tallamise motiivid Taara tammikutega. Võrreldes Macphersoni ja Kreutzwaldiga on Jakobson optimistlikum, öeldes: „Ei enam kurbuskeelil / Nüüd taha kaevata." Ta soovib Taara tammikutest kostva hääle toel taas vabadust taotleda: „Te' Taara muistsed tuuled, / Oh tõuske jälle teal!”; „Sest Taara tammikutes / Veel kuulen kanget healt; / Kõik ennemuistsed tuuled / Ei ole kadund sealt!" (Linnutaja 1870: 11) Luuletus on Aleksander Kunileiu viisistatuna levinud ka koorilauluna, mis on andnud sellele laiema kandepinna kui üksnes raamatus avaldatud tekstile: seda on peast teadnud mitu põlvkonda koorilauljaid ja kuulnud suur hulk kuulajaid pidulikel sündmustel. Jakobsoni Taara tammik viitab territoriaalselt kogu Eestile, mitte ühelegi konkreetsele paigale, tähistades kodumaad ja vabaduseiha üldiselt. Seda tammikut ei ole võimalik tee ääres näidata, erinevalt Kalevipoja heidetud kivist. Samal kombel esitab „püha pärnapuud” Gustav Wulff-Ôie kirjutatud koorilaul „Õrn ööbik” (sõnad Karl Rammi viisile, esmakordselt ilmus 1883. aastal Eesti Postimehe lisalehes). Siin on vastandatud mõisa õu ja püha pärnapuu talupoja akna all. Seegi on pigem rahvuse kujutletud pühapaik, mitte külakonna ühine mälupaik.

Näidet, kuidas linnamägede, kalmete ja osa looduslike pühapaikade muististena arvele võtmise ja maastikul tähistamise järgselt on jätkatud romantilist leiutatud traditsiooni, pakuvad ansambli Metsatöll plaadi „Hiiekoda” (Metsatöll 2004) mõne laulu sõnad. Laulus „Lahinguväljal näeme, raisk!” esinevad värsid „Täna lähme võitlemaie, / läbi hiie, läbi laane” ja „külmast kanged kivikalmed". Kodu, võitlus ja pühad tammed on mitmel puhul ühendatud hiie mõistega: „me hinges võitluses on hiiekoda / ja kodu Taara tammede all!” (laul „Merepojad”); „Ma mäletan sõda mis röövis mu aated / Ma mäletan sõda 
mis tormina laastas mu maad / Ma mäletan hiit kus ohvrina lamas mu isa / Ma mäletan hiit kus voolas mu vendade veri”, „Mu maa on minu hiie koda” (laul „Hiiekoda”).

Tänapäeva eesti kultuuris vastab igale Kreutzwaldi looduslike pühapaikade kujutamise viisile ka maastikupraktikate kimp. Esiteks: vanale suulisele traditsioonile on lähim pühapaikade dokumenteerimine ja meelespidamine konkreetsete maastikuobjektidena. See on endale aseme leidnud kirjakultuuri perifeerias, kus assimileeritakse suulisi tekste kirjaliku dominandiga kultuuri. Tähtsaimad info valdajad on siin head suulise kultuuri tundjad (vastandina on vast iga kohapärimuse koguja kohanud kirjakultuuri mallides mõtlevaid inimesi, kes suunavad ta muuseumi või raamatukokku või viitavad raamatule, kus olla kõik kirjas). Samuti kuulub sellele väljale koduloolaste tegevus, kes leiavad seoseid suulise maastikupärimuse ja kirjutatud rahvusliku ajaloo vahel ja kellelt pärineb hulk Henriku kroonikas mainitud paikade äratundmisi kohalike pärimuspaikadena.

Teiseks toimib Taara tammik rahvuse kujutletud, virtuaalse pühapaigana. Rahvusromantilist tammesümboolikat viljeletakse kinnitusega, et muistsete eestlaste püha puu oli tamm (vt lähemalt Heinapuu 2010). See suhtumine kannab edasi Kreutzwaldi moodi õhkamist kadunud muinaseesti hiite järele, näiteks lihtsustunud arusaamas, et hiied hävitati ristisõja ajal ja hiieasemetele on ehitatud kirikud, mistõttu peetakse hiisi praktiliselt kättesaamatuteks, kuigi tegelikult on Eestis avalikkusele kättesaadavad näiteks 452 kultuurimälestiseks tunnistatud ajaloolist looduslikku pühapaika (Eesti ajaloolised looduslikud pühapaigad 2008: 12).

Kolmandaks: „Kalevipoja” klassitsismile läheneva loodusekujutusega (Annist 2005: 829) sarnaneva pühapaikade käsituse jätkuks on viimasel ajal hoogu kogunud tava istutada tammikuid, millega viidatakse otse või kaude Taara tammiku mõistele. Selle üks varasemaid näiteid oli Teise maailmasõja eelne algatus rajada Sõjamäe hiis (vt Vakker 2012: 190-191). Praegu kannab see paik Jüriöö pargi nime, selle ümber on kasvanud Lasnamäe linnaosa. Pargi klassitsistlike sammastega tsiviilreligioosses rajatises tähistatakse igal aastal sõjaväeliste kombetalitustega vabariigi aastapäeva, võidupüha ja mälestatakse Jüriöö ülestõusu, samuti annavad seal pidulikult Eesti Vabariigile vannet Vahipataljoni noorsõdurid. Sarnase funktsiooniga on Harjumaale Loo alevikku rajatud Vabaduse hiis, mille kombestik on seotud maakaitsepäeva pidamisega 23. juunil. Hiis moodustub tammedest, mida on istutanud Harju maakonna omavalitsusjuhid ja Kaitseliidu Harju maleva juhatuse liikmed 2005. aastast alates. Paik on rajatud XI-XIII aastasajal kasutatud ja seega muistse vabadusvõitlusega seostatava Proosa kivikalme lähedusse (vt nt Loo aleviku arengukava 2010: 8). Aastail 2004-2007 Tartu linnapeana teeninud Laine Jänese (praegu Randjärv) algatusel on rajatud Tartu linna tammik, kuhu istutavad tammesid linna aukodanikud ja endised linnapead, seda nimetati mõtte idanemise aegu otsesõnu Taara tammikuks. Lisaks sellele on Eesti Vabariigi 100. aastapäeva tähistamiseks võetud Riigikantselei eestvedamisel istutada tammikuid üle Eesti. Säärased algatused seovad tänapäeva Eesti institutsioone muistsete Taara tammikutega.

Noori tammesid on suuremal hulgal istutatud vähemalt ühel juhul ka pärimuses tuntud vanasse pühapaika pärast seda, kui koduloolane Helmut 
Elstrok koos Viru-Nigula muinsuskaitseseltsiga algatas 1988. aasta sügisel Samma ehk Tammealuse hiie „taastamise” Viru-Nigula lähedal. Algatusega liitusid Tartu muinsuskaitseklubi Tõlet taara- ja maausuhuvilised. Sonda metskonna kaasabil toodi kohale tammeistikud, pilda ehk vitsaga määrati istutamiskohad ning 20. mail 1989 istutati Tõleti ja Viru-Nigula muinsuskaitseseltsi korraldusel sadakond noort tamme. (Kaasik 2017: 256; Heinapuu 2010: 128)

\section{Rahvuslik identiteet ja rahvusvahelised motiivid}

Et tasakaalustada rahvusliku eripära rõhutamist, tuleks meeles pidada, et nii kirjakultuur kui ka suuline kultuur on avatud suhtluseks oma lähemast kultuuripiirist väljaspoolsetega, kumbki on laiema rahvusvahelise kultuuripildi osa. Nii on rahvuslus olnud rahvusvaheline moenähtus, mis kohandab samu malle ja lugusid eri rahvustele, säilitades rõhuasetuse, et just see rahvus on eriline ja teistest erinev. Andersoni järgi oli rahvusluse kujunemiseks Euroopas ja sealhulgas Ida-Euroopas vaja kahte komponenti: rahvuslikku kirjakeelt ja rahvusvahelist rahvuse malli, mida „piraatluse” korras teistelt rahvustelt üle võtta ja kohalikele oludele kohandada (Anderson 2006: 67-82).

Eesti rahvuslus kordab ühe oma põhiloona varianti saksa rahvusluses tuntud suurest vabadusvõitlusest impeeriumi vastu (Schama 1995; Tamm 2012). Agressorist suurvõim üritab alistada vabadust armastavat ja looduslähedast väiksemat rahvast, mis lõpuks ei õnnestu. Loo saksa variandis on impeeriumi rolli täitnud nii Rooma impeerium (Rooma väepealike katsed alistada germaanlasi ja lüüasaamine Arminiuselt) kui ka Napoleoni Prantsuse keisririik. Eesti variandis on agressoriteks sakslased: saksa päritolu ristirüütlid ja hiljem Landeswehr. Säärast Andersoni nimetatud „piraatlust” leidub eesti rahvuse kujundamisel ka põhinarratiivist väiksemate ehituskivide juures.

Nii rahvuslus kui ka rahvalik usk on rahvusvahelise kultuurisüsteemi osad, mis võtavad lokaalselt eripäraseid kujusid, korraldades laiemalt levinud elemente kohalikesse konfiguratsioonidesse ja kohandades neid. Suulise folkloori ehitusklotsid on rahvusvahelised: värvikamad motiivid, lood ja uskumused rändavad ja on levinud laial alal ja paljudes keeltes. Samuti on Euroopa kirjakultuuris antiikajast saati palju ühist, mis on sugenenud ja püsinud üle keelepiiride käivas pidevas suhtlus- ja tõlkeprotsessis. Need kaks rahvusvahelist kultuuri põimuvad ka XIX aastasaja eesti rahvaluule üleskirjutustes, mis on üks suulise ja kirjaliku kultuuri omavahelise suhtluse paiku (vt nt Kikas 2010: 65-72).

Kuigi pühapaigad ja olulisena tajutud paigad on tugevalt seotud kohaliku identiteediga, on ka looduslikud pühapaigad üle ilma tuntud nähtus. Siiski tuleb ette, et jõukamatel aegadel on neisse pühakodasid ehitatud. Ka Akropoli mägi Ateena linna kohal on looduslik pühapaik, millele on rajatud templid, Paani koopaid mäekülje sees võib siiani pidada olulise inimmõjuta looduslikuks pühapaigaks. Praeguseks kõikjal kättesaadavate Akropoli templite pildid on varjutanud teadmise, et usulised toimingud mäel keskendusid varem linna kaitsja Athena õlipuule ja väikesele soolase veega lohule, mis 
märgib kohta, kus maad tabas Poseidoni kolmhark lahingus, milles veejumal jäi alla Athenale, kes siis sai Ateena kaitsjaks. Kuigi lohu ümber on ehitatud Erechteioni tempel, pidi lohk jääma taevale avatuks. (Burkert 1985: 85-87)

Samamoodi, kui pühadele mägedele ehitatakse jõukuse ja poliitilise tahte toel või religioonivahetuse ajel pühakodasid (ka varasemaid usulisi keelde rikkudes), võib püha allikas saada kaevurangid (nt Karkuse hiiekaev Ambla kihelkonnas, vt Remmel 1998: 135) või purskkaevu - mitmel pool LääneEuroopas on kombeks purskkaevudele münte ohverdada nagu allikatesse või siis muutuda linnapargi tiigiks, nagu on juhtunud Soomes Turu linnas Kupittaa allikaga, mis on pärimuse järgi seotud Soome ristiusustaja piiskop Henrikuga ning oli ilmselt püha allikas ka ristiusustamise eel. On hakanud kõlama väited, nagu oleks Euroopa looduslikud pühapaigad enamasti hävinud (nt Ramakrishnan 2003). See üldistus võib laias plaanis paika pidada (kui võrrelda tööstusrevolutsiooni järgset Lääne-Euroopat teiste maailmajagudega, vt nt Valk 2017: 151-155), kuid selle vaatenurga tasakaalustamiseks võib viidata Simon Schama käsitlusele, mille eesmärk on näidata õhtumaiste traditsioonide varal, et „inimsoo kultuurilised harjumused on alati jätnud ruumi looduse pühadusele" (Schama 1995: 18).

Kreeka kultuur avastas oma ajaloolise sügavuse romantismiajal, kui klassikaline kirjavara sai ligipääsetavaks kreeka haritlastele eksiilis ja kodumaal; sellele järgnes pärast iseseisva Kreeka kuningriigi asutamist uue kreeka kultuuri loomine, mis pidi olema antiikse vääriline (Anderson 2006: 72-73). Ühise mälu olulisust vene rahvuse kujunemisel on märkinud Juri Lotman: „Ühise rahvusliku mälu olemasolu oli märgiks rahvuskollektiivi eksistentsist ühtse organismina" (Lotman 2010: 34). Samalaadset rolli, nagu antiikne kirjavara kreeka kultuuris, on eesti kultuuris mänginud ehk enim üksiku tekstina Henriku Liivimaa kroonika, mis on andnud lähtekohad eesti kultuuri ajaloolise sügavuse ning muistse eesti kultuuri väljajoonistamiseks, vastavalt romantismiaja arusaamadele. Nii on loodud rahvuse ühist mälu, mis pidi kohalikud kogukonnad liitma üheks rahvuskogukonnaks. Tegu on leiutatud traditsiooniga Eric Hobsbawmi (1983) mõttes, mis tekkiva ühiskonna rahvuseks kokku liidab.

Ärkamisajajärgne eesti identiteet ja selle tähistamise viisid on suures osas rajatud XIX sajandi romantismi vaimus loodud müütidele. Tänapäeva eesti identiteet eeldab rahvuse kujutletud kogukonda. Erinevalt sunnismaise agraarühiskonna paikkondlikult kokkukuuluvast külakogukonnast, mida ühendasid maakasutus ja sugulus- ning põlvnemissuhted, hoiab rahvuse kujutletud kogukonda koos ühine kirjutatud ajalugu, mida levitatakse kooliõpikute kaudu. Nähtavates ja kogetavates paikades muinasaega rahvusliku mäluga siduvaid mälupaiku on loodud pärast 1920. aastat, säärased mälupaigad on aidanud Eesti riiki legitimeerida ja eestlastel minna lähemale oma rahva kujutletud muistsetele juurtele. ${ }^{3}$ Eesti rahvuslikule identiteedile olulised maastikumärgid erinevad paikkondlikest maastikumärkidest, mis olid olulised agraarsetele kogukondadele.

3 „Mälupaigad saavad alguse tundest, et ei ole spontaanset mälu, et me peame tahtsi looma arhiive, pidama aastapäevi, korraldama pidustusi, esitama ülistuskõnesid, notariaalselt tõestama ostu-müügiakte, kuna selliseid asju ei tule enam loomulikult ette," on märkinud Pierre Nora (1989: 12). 
Eesti looduslike pühapaikade kujutamisel on kirjakultuuri eri traditsioonide vaheline dialoog olnud viljakam kui tõlge suulisest kultuurist kirjalikku. Tänapäeva eesti kirjakultuuris valitsevad looduslike pühapaikade motiivid, nagu püha tammepuu või tammik Taarale pühendatud hiiesaluna, pole mitte eesti kultuurile ainuomased, vaid on pärit kirjakultuurist ja levinud kogu Euroopas. Siiski on nende motiividega nüüdseks seotud allusioon, justnagu kannaksid nad midagi eesti kultuurile ainuomast. On paradoksaalne, et kimp märke ja motiive, mis kuuluvad tugevaimate rahvusliku identiteedi tähistajate hulka ja kannavad eestluse ürgse ja kõige põlisema tuuma tähendust, on õigupoolest laenatud Euroopa rahvusvahelisest kultuuripärandist, millele on kombeks muistsele eestlusele viidates pigem vastanduda.

Rääkides sümboolsetest maastikest, märgib Kati Lindström, et eesti ja läti rahvussümbolid on väga sarnased, kuid neid tajutakse puhtalt eesti või puhtalt läti sümbolitena, lugedes Edmunds V. Bunkše (1999, 2004) järgi näidetena üles eraldi talukohtade kujutised ühes äratuntavate ehitiste ja ümbritsevate põldude-metsadega, hajaasustuse mustrid, suured tammepuud, lilleaasad ja võimsad rändrahnud (Lindström 2008: 228).

Haritlaste ringist on koos rahvusliku ideoloogia, eestikeelse kirjavara ja ametliku haridusega laiemalt levinud looduslike pühapaikade mõistmise mall, mis allutab endale kohalikke pühapaiga- ja muid maastikutraditsioone. Pärimusmaastike tõlgendamisel on kirjanduslikku päritolu motiivid ladestunud uue kihina paikkondlikku kohapärimusse (vrd nt Metssalu 2008). Ülo Valgu sõnul (2012: 856) nähti romantismiajal folklooris muinaspärandit, mis löödi lahku selle kandjatest, esitajatest ja nende argielust. Hiiemäest saab muistse vabadusvõitluse mälestis, mille juures pole enam oluline kohaliku tähtsusega üleloomulike olendite lepitamine uudseandidega ega talupoja argielulised õnne- ja tervisemured („argielu kordaminek”, vt Valk 2017: 143). Pühast männitukast võib rahvuslikult ärganud kirjatundja abiga saada Lembituaegne Taara tammik.

\section{Looduslikud pühapaigad tänapäeva kultuuris}

Kohaliku traditsiooni osad, mis ei ühildu valitseva malliga, võivad kaduda või nihkuda kultuuri perifeeriasse - mittekultuuri ehk kultuuri unustatud või tõrjutud ossa, mis funktsionaalselt kuulub küll kultuuri hulka, kuid ei täida selle reegleid (Lotman 2010: 31). Eesti pühapaigad, mis haakuvad kinnistunud rahvusliku ideoloogiaga halvemini, ei leia väärtustamist võrdväärselt nendega, mis seonduvad paremini muistse vabadusvõitluse või tammesaludega. Pühade tammede hegemoonia kirjakultuuris võib raskendada juurdepääsu varasemale pärimusele, juhul kui on omaks võetud arusaamine, et pühapaik peaks olema eelkõige tammik. Nii võib muistse priiuseaja paleus takistada lähema mineviku talupojakogukonna maastikupärimuse mõistmist.

Tänapäeva kultuuri seisukohalt on küsimus selles, kas ja mil viisil rahvaliku usu looduslikud pühapaigad on tähenduslikud: kas nad on pelgalt materiaalse elu faktid ehk mittemärgid või on neil täiendav sotsiaalne ehk märgiline mõte, laenates väljendust Lotmanilt (2010: 38). Võib küsida, millistele kultuuri allsüsteemidele vanad looduslikud pühapaigad tähenduslikud on. 
Pühapaiku võib mõtestada a) rahvaliku usu kontekstis ehk kogukonnas suuliselt ja jäljendamisega edasi antud traditsiooni jätkates; b) olulise nähtusena territoriaalselt hajusa ja väikese grupi kultuuris (nt maausulised ja taarausulised); c) loodusväärtustena; d) ajaloolise või rahvusliku mälu kandjatena või e) kohaliku kogukonna kokkukuuluvust tähistavate märkidena.

Sellest, kuidas ja kas nende süsteemide kultuurikoodid on vastastikku tõlgitavad või arusaadavad, sõltub, kas kultuuri eri allsüsteemid on omavahel kooskõlas või konfliktsed. Kui tähistused on vastastikku tõlgitavad, võib rahvusliku mälu ühine pind anda võimalusi säilitada allsüsteemide ühisosa. Konflikte võib sündida siis, kui kirjakultuuril põhineva ruumilise planeerimise korra kujundajad ei tunnista suulist kultuuri võrdväärse vestluspartnerina ja suuline kultuur jääb nende jaoks mittekultuuri ning vastupidi, suulise kultuuri tundjate ja väärtustajate jaoks jääb ametkondlik asjaajamine bürokraatlikku mittekultuuri, mis ahendab omavahelise mõtteka dialoogi võimalusi. Suulist maastikupärimust võib ka pärast kirjapanemist pidada ebausaldusväärseks, kuna see ei vasta samadele tõeväärtuse kriteeriumidele kui kirjaliku asjaajamise dokumendid. Juhul kui vanu pühapaiku ei tunta enam väärtuslikena ja pole kergesti kättesaadavaid kirjalikke jälgi nende staatusest pühapaikadena, võib teadmatus avada tee nende paikade materiaalsele ümberkujundamisele, isegi kui arhiivides või erialakirjanduses on olemas raskemini kättesaadavaid üleskirjutusi neid paiku puudutavast suulisest pärimusest, mis ei kuulu enam käibivasse kultuuri.

Üldjuhul ei ole suulisel kultuuril, erinevalt kirjalikust, täpset, aastasadade taha ulatuvat ajaloolist mälu (Ong 2002: 64-69, 78-98). Kohaliku kirjakultuuri arenedes nähti vajadust koguda, luua või leiutada eesti rahvusele teiste kirjakultuuridega võrreldav ajalooline mälu, kuna kirjalik kultuur vajab ajaloolist sügavust. See annab võimaluse vanema traditsiooni elementidel kohaneda ja edasi kesta, ristudes uuemate kultuurinähtustega ja leides oma koha uues kultuurisüsteemis. Osa varasemat suulist pärimust on maastiku, ühiskonna ja kultuuri muudatuste tõttu jäänud mittekultuuri ning seejärel kas käibelt kadunud ja säilinud üksnes sõnadena paberil (kirjalikult talletatud pärimus) või siis jäljetult kadunud (talletamata suuline vm käitumuslik pärand). See kinnitab Lotmani tähelepanekut, et „ainult ühte või teise märkide süsteemi üleviidu võib saada mälu omanduseks [---]. Ei ole juhuslik, et igasugune kultuuri hävitamine kulgeb läbi mälu hävitamise, tekstide puhastamise ja seoste unustamise." (Lotman 2010: 33)

Kirjakultuurile aktsepteeritava ajalise sügavuse andmiseks oleks raske looduslike pühapaikade kasutuselevõtu aega dateerida üksnes suulise pärimuse põhjal, kuna traditsiooniline pühapaik võib olla olnud kasutuses tuhat või sada aastat (vt nt Jonuks jt 2014). Puht teadusliku metodoloogia vaatenurgast oleks täpsema uurimiseta ebakorrektne eeldada nii seda, et kõik teadaolevad traditsioonilised looduslikud pühapaigad on kasutusele võetud suhteliselt hiljuti, kui ka seda, et need paigad on pühad olnud väga kaua. Dateerida tuleks iga paika eraldi, ühendades pärimusteaduste, arheoloogia, ajaloo ja loodusteaduste meetodeid (vt ka Äikäs 2011; Valk 2007; Leibak 2007), võttes arvesse paiga liigikooslusi, kohanimeajalugu ning muid kaudsemaid andmeid. Põhjalikumate uuringutega valmiva representatiivse valimi pühapaigabiograafiate 
põhjal saaks teha järeldusi Eesti looduslike pühapaikade ringluse ajaloolise dünaamika ja kiiruse kohta.

Domineeriva kultuurikoodi vahetus on langenud ühte maastiku murrangutega (linnastumine ja maaomandi-maakasutuse ümberkorraldamine), mis kokku tähendab üleminekut ühelt kultuuritüübilt teisele, samuti kui murrangud, millest vene kultuuris räägib Lotman (2010: 40-60). Eesti looduslike pühapaikade saatus kinnitab Denis Cosgrove’i (1998) teesi, et iga ühiskonnakord loob endale ise sümboolsed maastikud. Siiski säilib kultuuris ajas muutunud kujul olulistena vanu maastikke või vähemalt nende elemente, nagu näiteks maharaiumisest pääsenud osa hiiest või üksik pühapuu või hävinud pühapuu kohale kasvanud uus puu (nt Ülendi hiiepärn Hiiumaa lääneotsas), kuigi neid mõtestatakse teisiti kui varem.

Arhiividesse kogutud kohapärimuse digiteerimine ja looduslike pühapaikade inventeerimine annab võimaluse praegustele kogukondadele ja huvirühmadele sääraste varasemates ühiskonnakordades oluliste maastikega suhestuda ja neid ära tunda, nii et maastikutundmises võiks püsida järjepidevus ka hoolimata ühiskondlike olude muutumisest.

\section{Kokkuvõtteks}

Suulises agraarkultuuris on looduslikud pühapaigad osa pärandmaastikust: igapäevase maakasutuse tavadega põimuvad pärimuses mütoloogilised motiivid ja maailmakorda selgitavaid lood (sh rahvusvahelise levikuga motiivid ja süžeed), mis on seotud konkreetsete kohtadega. Sel kombel hoiab pühapaikade pärimus maailma sidusust, kogukondlikud ühised rituaalid pühapaikades aga ka kogukonna sidusust ja kogukonnale olulisi suhteid üleloomulike olenditega.

Seevastu eesti kirjalikus kultuuris on vanema maastikupärandi hulka kuuluvad looduslikud pühapaigad, aga ka looduslike pühapaikade või vastavate antiiksete või Lääne-Euroopa sümboolsete maastike eeskujul uuemal ajal loodud maastikud asunud tähistama kaugemat rahvuslikku minevikku, mis enamasti seostub muistse vabadusvõitluse eelsete ja aegsete sündmustega. Kohalikud pärimuspaigad toetavad sedakaudu rahvuslikku identiteeti.

Samal ajal valitseb eesti kirjakultuuris pühapaikadest kõnelemise viis, mis ühendab eesti kultuuri baltisaksa kirjakultuuri kaudu ülejäänud LääneEuroopa ja antiigi pärandiga. Seda kinnitab ka „Kalevipoja” teksti lähem vaatlus. Looduslikest pühapaikadest nimetatakse eepose tekstis otsesõnu kõige enam tammikuid. Enamasti esinevad Taara tammikud eeposes idealiseeritud muistse priiuseaja hõllandustena ning neid viiteid on raske siduda konkreetsete kohtadega ruumis. Säärane hiitest ja muudest looduslikest pühapaikadest kõnelemise viis, mis igatseb taga maharaiutud pühi tammesalusid, esineb tihti ka hilisemates kultuuritekstides. Erandlikult viitab „Kalevipoja” tekst täpsemalt hiiele Saadjärve lähistel ja ilmselt ka Tartu Toomemäele, mida on võimalik konkreetsete paikadena tuvastada.

Viited Uku kivile ohverdamisest kannavad eepose tekstis sarnast antiikset-heroilist vaimu kui pühad tammesalud. Kuid teisalt on kangelaseepose keelde tõlgitud ka teksti kohapärimusse kuuluva muistendivaraga ühendav lugu Iru ämma ning Ülemiste järves oleva rändrahnu sünnist. Sarnaselt kan- 
dub kirjakultuuri tekstide allhoovustes edasi ka üksikasjalikku kohapärimust, mis sel viisil leiab kokkupuutepunkte uuemale kirjakultuurile omase maastike mõtestamise kontseptuaalse süsteemiga. Niisugused kokkupuuted on näited sellest, kuidas kultuuri suuline ja kirjalik allsüsteem omavahel suhtlevad, nii et tekste tõlgitakse ühest allsüsteemist teise. Kuid tõlke käigus tekstid ja motiivid muutuvad, et kohaneda allsüsteemiga, millesse neid tõlgitakse. Sel kombel kujunenud maastikukäsitus annab omakorda võimaluse hakata looma uusi sümboolseid maastikke, mis sobiksid kirjeldatud elementidest sündinud käsitusega paremini kui vanemas suulises kohapärimuses kirjeldatud paigad.

\section{Arhiiviallikad}

Eesti Kirjandusmuuseum (EKM), Eesti Rahvaluule Arhiiv (ERA) E - Matthias Johann Eiseni rahvaluulekogu

\section{Kirjandus}

Anders o n, Benedict 2006. Imagined Communities. Reflections on the Origin and Spread of Nationalism. Revised edition. London-New York: Verso.

Annist, August 2005. Friedrich Reinhold Kreutzwaldi „Kalevipoeg”. Toim Ülo Tedre. Tallinn: Eesti Keele Sihtasutus.

Bunkše, Edmunds V. 1999. Reality of rural landscape symbolism in the formation of post-Soviet, postmodern Latvian identity. - Norsk Geografisk Tidsskrift - Norwegian Journal of Geography, kd 53, nr 2-3, lk 121-138.

Bunkš e, Edmunds V. 2004. Of oaks, erratic boulders, and milkmaids: The poet Imants Ziedonis and art as mediator between discourses about rural landscapes. - European Rural Landscapes: Persistence and Change in a Globalising Environment. Toim Hannes Palang, Helen Sooväli, Marc Antrop, Gunhild Setten. Dordrecht: Springer, lk 137-149.

Burkert, Walter 1985. Greek Religion. Tlk John Raffan. Cambridge, MA: Harvard University Press.

Cosgrove, Denis E. 1998. Social Formation and Symbolic Landscape. 2nd edition. Madison: Wisconsin University Press.

Eesti ajaloolised looduslikud pühapaigad. Uurimine ja hoidmine. Valdkonna arengukava 2008-2012. Tallinn: Kultuuriministeerium, 2008. https:/www.kul.ee/ sites/kulminn/files/looduslikud_pyhapaigad_arengukava_2008_2012.pdf (17. II 2019).

Eesti looduslikud pühapaigad. Uurimine ja hoidmine. Valdkonna arengukava 20152020. Tallinn: Kultuuriministeerium, 2015. https:/www.muinsuskaitseamet. ee/sites/default/files/content-editors/ALPAK/alpak_arengukava_2015-2020.pdf (17. II 2019).

Eis en, Matthias Johann 1920. Eesti kohalikud muistejutud. Tallinn: Eestimaa Kooliõpetajate Vastastiku Abiandmise Seltsi raamatukauplus.

Eisen, Matthias Johann 1996 [1918]. Esivanemate ohverdamised. Toim Ülo Tedre. Tallinn: Mats. 
Eisen, Matthias Johann 2000 [1958]. Esivanemate varandus. Kordustrükk. Koost, toim Herbert Tampere. Tallinn: Sinisukk.

HCL = Heinrici Chronicon Livoniae. Henriku Liivimaa kroonika. Tlk Richard Kleis, toim ja komm Enn Tarvel. Tallinn: Eesti Raamat, 1982.

Hein a pu u, Ott 2010. Taara tammikud: ideaalse pühapaiga tung tekstist maastikule. - Acta Semiotica Estica, kd 7, lk 102-138.

Heinapuu, Ott 2016. Agrarian rituals giving way to Romantic motifs: Sacred natural sites in Estonia. - Sign Systems Studies, kd 44, nr 1-2, lk 164-185.

Heinapuu, Ott 2018. Reframing sacred natural sites as national monuments in Estonia: Shifts in nature-culture interactions. - Framing the Environmental Humanities. Toim Hannes Bergthaller, Peter Mortensen. Leiden: Brill, lk 86-102.

Hobsbawm, Eric 1983. Introduction: Inventing traditions. - The Invention of Tradition. Toim E. Hobsbawm, Terence Ranger. London: Cambridge University Press, lk 1-14.

Ho m e r o s 1960. Ilias. Tlk August Annist. Tallinn: Eesti Riiklik Kirjastus.

Ingold, Tim 2000. The perception of the environment. London: Routledge.

Jon uks, Tõnno 2007. Holy groves in Estonian religion. - Estonian Journal of Archaeology, kd 11, nr 1, lk 3-35.

Jonuks, Tõnno, Veldi, Martti, Oras, Ester 2014. Looduslikud pühapaigad uue ja vana piiril. - Vikerkaar, nr 7-8, lk 93-108.

Ka a sik, Ahto 2017. Pühapaikade teejuht. Eesti põlised väekohad. Tallinn: Pegasus.

Ki k a s, Katre 2010. Rahvaluulekoguja raamatuid otsimas. Hans Anton Schults. Acta Semiotica Estica, kd 7, lk 64-101.

Koski, Mauno 1967. Itämerensuomalaisten kielten hiisi-sanue. I kd. Turku: Turun yliopiston julkaisuja.

Kreutzw ald, Friedrich Reinhold 2003 [1862]. Kalevipoeg. Üks ennemuistne jutt kahekümnes laulus. 18. trükk. Tallinn: SE\&JS.

La a nes, Eneken, Kaljundi, Linda 2013. Eesti ajalooromaani poeetika ja poliitika. Sissejuhatuseks. - Keel ja Kirjandus, nr 8-9, lk 561-578.

La ugaste, Eduard, N or mann, Erna 1959. Muistendid Kalevipojast. Tallinn: Eesti Riiklik Kirjastus.

Leibak, Eerik 2007. Hiied kui loodusobjektid. - Looduslikud pühapaigad: Väärtused ja kaitse. Koost Ahto Kaasik, Heiki Valk. Tartu: Tartu Ülikool, Maavalla Koda, Õpetatud Eesti Selts, lk 173-182.

Lindströ m, Kati 2008. Landscape image as a mnemonic tool in cultural change: The case of two phantom sceneries. - Koht ja paik. Place and Location. Studies in Environmental Aesthetics and Semiotics VI. Toim Eva Näripea, Virve Sarapik, Jaak Tomberg. Tallinn: Estonian Academy of Arts, Estonian Semiotics Association, lk 227-238.

Linnutaja 1870 = Lauliku C. R. Linnutaja laulud. Esimene krantsikene. Tartu: H. Laakmanni kulu ja kirjadega trükkitud.

Loo aleviku arengukava 2010-2020. Jõelähtme vald: Loo aleviku eestseisus, 2010. http://www.looalevik.ee/wp-content/uploads/2012/05/LOO_ALEVIKU_ARENGUKAVA-2010-2020.pdf (16. III 2019).

Looduslikud pühapaigad. Juhend kaitsealade valitsejatele. Kaitsealade kultuuriliste ja vaimsete väärtuste töörühm koostöös UNESCO programmiga „Inimene 
ja biosfäär”. (Maailma Kaitsealade Komisjon. Kaitsealade hea tava suunised 16.) Toim Richard Wild, Christopher McLeod. Tlk Anna-Liisa Lutsar. Tartu: Taarausuliste ja Maausuliste Maavalla Koda, Keskkonnainvesteeringute Keskus, 2011. https://www.muinsuskaitseamet.ee/sites/default/files/content-editors/ALPAK/iucn_sns_estonia.pdf (17. II 2019).

Lotman, Juri 2010. Kultuuritüpoloogiast. Tlk Kadri Tamm, Tanel Pern, Silvi Salupere. Tartu: Tartu Ülikooli Kirjastus.

L ow enthal, David 1985. The Past is a Foreign Country. Cambridge: Cambridge University Press.

Meriste, Valev 1976. Kalevipoja lingukivid Saadjärve ääres. - Eesti Loodus, nr $6,1 \mathrm{k} 408-410$.

Metsatöll 2004. Hiiekoda. [CD-plaat.] Tallinn: Nailboard Records.

Metssalu, Jüri 2008. Ajalookirjutuse mõjust kohapärimusele Raikküla näitel ehk katse tuvastada maa-alune tee munkade juurest muistsete vanemateni. Kes kõlbab, seda kõneldakse. Pühendusteos Mall Hiiemäele. Toim Eda Kalmre, Ergo-Hart Västrik. Tartu: Eesti Kirjandusmuuseum, lk 317-353.

MuKS = Muinsuskaitseseadus. Riigi Teataja I, 19.03.2019, 13. https://www.riigiteataja.ee/akt/119032019013

N o r a, Pierre 1989. Between memory and history: Les Lieux de Memoire. - Representations, kd 26, Spring, lk 7-24.

O in a s, Felix 1994. Kalevipoeg kütkeis. - F. Oinas, Surematu Kalevipoeg. Tallinn: Keel ja Kirjandus, lk 11-37.

Ong, Walter J. 2002. Orality and Literacy: The Technologizing of the Word. London-New York: Routledge.

Philostratorum Imagines et Callistrati Statuae. Toim Friedrich Jacobs. Leipzig: Libraria Dyckiana, 1825.

Puss, Fred 1995. Puudega seotud pärimused ja traditsioonid Eesti rahvakultuuris. Proseminaritöö. Käsikiri Eesti Kirjandusmuuseumis.

Pühad kivid Eestimaal 2011. Koost Mall Hiiemäe. Tallinn: Tammerraamat.

Ramakrishnan, Palayanoor Sivaswamy 2003. Conserving the sacred: The protective impulse and the origins of modern protected areas. - The Full Value of Parks: From Economics to the Intangible. Toim David Harmon, Allen D. Putney. Lanham, MD: Rowman \& Littlefield, lk 27-42.

Re m mel, Mari-Ann 1998. Hiie ase: hiis eesti rahvapärimuses. Tartu: Eesti Kirjandusmuuseum.

R e m m el, Mari-Ann 2005. Iru Ämm ja Linda kivi. - Eesti Loodus, nr 6, lk 38-40.

R e m m el, Mari-Ann 2014. Kohapärimuse mõiste, uurimislugu ja tunnusjooned. Muistis, koht ja pärimus. II kd. Pärimus ja paigad. Tartu: Tartu Ülikool, ajaloo ja arheoloogia instituut, arheoloogia osakond, lk 13-70.

Sch a m a, Simon 1995. Landscape and Memory. New York: Vintage Books.

Sutrop, Urmas 2002. Taarapita - saarlaste suur jumal. - Mäetagused, nr 16, lk 7-38.

T a m m, Marek 2012. Monumentaalne ajalugu. Esseid Eesti ajalookultuurist. Tallinn: SA Kultuurileht.

Vakker, Triin 2012. Rahvusliku religiooni konstrueerimise katsed 1920.-1930. aastate Eestis - taara usk. - Mäetagused, kd 50, nr 1, lk 175-198. 
V alk, Heiki 2007. Looduslikud pühapaigad kui muistised: arheoloogia vaatenurk. - Looduslikud pühapaigad. Väärtused ja kaitse. Koost Ahto Kaasik, H. Valk. Tartu: Tartu Ülikool, Maavalla Koda, Õpetatud Eesti Selts, lk 135-182.

Valk, Heiki 2017. Eesti maarahva kultuuripildist keskajal ja varauusajal arheoloogia andmetel: olud ja koht laiemal taustal. - Eesti Vabariigi preemiad 2017. Teadus. F. J. Wiedemanni keeleauhind. Kultuur. Sport. Tallinn: Eesti Teaduste Akadeemia, lk 138-161.

V alk, Ülo 2012. Regivärsist rahvuslikku esoteerikasse. - Keel ja Kirjandus, nr 11, lk 854-858.

Äikäs, Tiina 2011. From fell tops to standing stones: Sacred landscapes in Northern Finland. - Archaeologica Baltica, kd 15, nr 1, lk 16-22.

Ott Heinapuu (snd 1979), ottheinapuu@gmail.com

\section{Estonian sacred natural sites in oral and literary culture on the example of the Estonian epic Kalevipoeg}

Keywords: nationalism, landscapes, site heritage, Estonian National Awakening, semiotics of culture, cultural typology

The article demonstrates differences between the symbolic landscapes of an oral vernacular culture and a literate culture, drawing on examples of perceiving and depicting sacred natural sites in Estonia. Vernacular oral culture and written national culture are considered as subsystems of a wider cultural system, following Yuri Lotman. In the literate Estonian culture from the $19^{\text {th }}$ century onward, references to oak groves dominate as a typical image of ancient Estonian sacred sites. The symbol of the sacred oak grove is literary in origin, deriving from European examples of the Romantic Era. An important source contributing to the spread of the idea of ancient oak groves has been the Estonian national epic Kalevipoeg by Fr. R. Kreutzwald, first published as a full edition in 1862. An analysis of the text of the epic shows that most references to sacred oak groves and oaks in the epic are rhetorical in nature, featuring as poetic devices, figures of speech or abstract symbols signifying the idea of an ancient golden era. Only in two instances can they be considered to refer to concrete landscapes that can be precisely located. In the $20^{\text {th }}$ century, sacred natural sites known to the local vernacular religion are increasingly interpreted in written national history as monuments of pre-Christian times. This is evidence of the hybridisation of certain features of written and oral culture after the national written culture has become established as the dominant subsystem.

Ott Heinapuu (b. 1979), ottheinapuu@gmail.com 